\title{
Comment
}

\section{Inclusão: Percepção dos professores}

\author{
Eliete Lira Nobre Ferreira ${ }^{1}$; Emídia Inácio Timóteo ${ }^{2}$; Martha Maria Macêdo Bezerra ${ }^{3}$
}

Resumo: Este estudo pretende analisar questões sobre a educação inclusiva. Discute principalmente aspectos históricos do movimento de inclusão e suas repercussões na sociedade atual. No que se refere a percepção dos professores na literatura, observou-se que uma maioria professores ainda julga os alunos sem deficiência como superiores àqueles que possuem alguma deficiência, considerem que a educação inclusiva precisa favorecer a socialização, base para a melhoria da qualidade da aprendizagem dos alunos com deficiência.

Palavras-chave: Educação inclusiva. Atitudes. Professores.

\section{Inclusion: Perception of teachers}

\begin{abstract}
This study aims to analyze questions about inclusive education. Especially discusses historical aspects of the inclusion movement and its impact on society today. Regarding the perception of teachers in the literature, we found that a majority of teachers still thinks that students without disabilities are superior to those with a disability, considerthat inclusive education must favor the socialization, the basis for the improvement of learning quality students with disabilities.
\end{abstract}

Keywords: Inclusive education. Attitudes. Teachers.

\section{Introdução}

Os movimentos sociais ligados à educação com vistas a inclusão encontram-se historicamente relacionados à luta pelos direitos civis, notadamente ao que é mais conhecido como a inclusão daqueles que são marginalizados socialmente. Em outros países como a Itália, segundo Sanz del Rio (1996), estão associados ao processo de desospitalização psiquiátrica.

\footnotetext{
${ }^{1}$ Professora, Secretaria de Educação do Estado do Ceará.

${ }^{2}$ Mestranda em Ciências da Educação pela Universidade Anne Sullyvan.

${ }^{3}$ Mestrado em Educação pela Universidade Estadual do Ceará. Pedagoga pela Universidade Regional do Cariri, Especialização em Língua Portuguesa pela Universidade Estadual do Ceará, Especialização em Políticas Públicas pela Universidade Regional do Cariri, Especialisação em Saude Mental e Psiquiatria pela Universidade Estadual do Vale do Acaraú. Atualmente, cursa o Doutorado em Saúde Coletiva pela Faculdade de Medicina do ABC. Professora concursada da Secretaria de Educação do Estado do Ceará e Professora da Rede Municipal de Juazeiro do Norte, CE. E-mail: marthamacedo2016@gmail.com
} 
Id on Line Revista Multidisciplinar e de Psicoloqia

Id on Line Multidisciplinary Journal and Psycology

Segundo Martins (1997), a estrutura da sociedade tem sido responsável por uma constante exclusão de diversos grupos. Uma análise capitalista da sociedade do século XIX, proposta por Marx (1867/1984), já evidenciava uma marginalização dos trabalhadores em relação ao sistema social e a segregação dos trabalhadores industriais. Estes, na época, viviam em condições sub-humanas, precárias e prejudiciais à saúde física e mental. Posteriormente, mulheres e crianças começam a adentrar o mundo do trabalho, passando também pela exploração de suas condições. As crianças perdiam oportunidades de educação, em detrimento de alguns, para que pudessem ter uma vida confortável. Dessa forma, outra parcela significativa da população, passava a contentar-se com sobrevivência, ficando feliz, quando conseguia encontrar um trabalho, seja ele qual fosse.

Segundo Adorno (1959/1972), homens passaram a parecer-se entre si em um nível sociopsicológico, porém não nas condições de vida. A ideologia de uma pseudo integração, conforme orienta Adorno, não admitiria que alguém ficasse de fora: era uma espécie de previdência social que deveria alcançar a todos (Horkheimer e Adorno, 1947/1985).

No campo da educação, as pessoas mais pobres passaram assim a ser contempladas com um mínimo do que era oferecido à elite social. Mesmo assim, a um preço de serem reduzidas a meras mercadorias. A produção do ensino de massa, não era voltado para a diferenciação individual. Esta passa a surgir com a incorporação da cultura. Na sua falta, continua externa aos indivíduos. A tecnologia começa a fazer parte da educação, que impõe métodos e simplifica o conhecimento, de maneira a se poder prescindir da qualificação dos professores. A mudança transforma a escola em uma transmissora de informações, evitando-se uma formação que deveria ir além do que já existe. Esta atitude parece coerente com o que descreve Benjamin (1938/1989) sobre o que seria transformação da experiência em vivência. Durante o século XIX, segundo Adorno (1959/1972), as informações rapidamente são substituídas por outras novas. É preciso estar-se a todo instante atualizado, mas apenas, com o conhecimento necessário para lidar com as máquinas. E esses logo são ultrapassados.

Dessa maneira, a formação de indivíduos se assemelha a uma pseudoformação, que se expressa em pelo menos duas tendências não antagônicas: a) uma formação para a adaptação e, uma formação somente pela formação. A primeira teria como objetivo principal a formação para atender o mercado de trabalho. Servindo para o mundo existente, porém não para a vida, proporcionando uma visão mais crítica. A pseudoformação, não ajuda a se pensar a sociedade 
Id on Line Revista Multidisciplinar e de Psicoloqia

Id on Line Multidisciplinary Journal and Psycology

como um produto da História. A outra modalidade, a cultura perde sua relação com a História social, por não estar relacionada com as necessidades dos homens. Converte-se pois, em mercadoria. As pessoas podem querer adquiri-la para ter e, dessa forma, passar a impressão de estarem incluídas porque estariam atualizadas.

O desenvolvimento dos recursos tecnológicos, do conhecimento e da riqueza, não destruiu as relações de produção capitalistas, assim como Marx (1867/1984) previa, pelo contrário, quando incorporados por essas, implicou num progresso contínuo e sem fim. Ironicamente, servindo mais predominantemente a um uso político, com vistas a manutenção dos interesses sociais dos mais ricos (Adorno, 1964/1995), mesmo que em alguns casos, trouxessem benefício para todos. A educação escolar passa a atender mais ao trabalho, e o nível de escolaridade que é exigido para algumas das funções do mercado, nem sempre é adequada ao que se necessita em termos de qualificação.

Segundo Lessa et al. (1997), muitas pessoas com diploma universitário atuam em atividades que não necessitaria de tal título. No plano político, continuamente, o estado de bemestar social, que fora criado pelo capitalismo ocidental, com a finalidade de competir com o socialismo, passa a dar lugar a um neoliberalismo. Este, ao contrário do liberalismo, não propõe a liberdade do mercado, mas impõe a função fiscalizadora do Estado (APPLE, 2002).

Essas modificações sociais eliciam o entendimento dos movimentos das minorias. A questão da competência deixa de ser valorizada. A organização da produção já pode ficar sob a tutela de uma administração eficiente, que pode não precisar dos homens. Marx (1867/1984) orientava que, com o desenvolvimento da maquinaria, os trabalhadores passaria a um mero apêndice. E com o desenvolvimento da tecnologia, eles se tornariam facilmente substituíveis por muitos outros. Isso aconteceria em outras dimensões da vida, inclusive na educação.

A educação inclusiva teve seu fortalecimento, principalmente, na década de 1990 (SANZ DEL RIO, 1996. Possibilitava, no limite, um entendimento de que deveriam as minorias serem incluídas. Daí o surgimento de um movimento para esclarecimento popular, insistindo na escola como lugar de uma educação voltada para a resistência à opressão. Para uma educação que leva em conta a percepção das contradições sociais, de forma a não negá-las. Sabedores somos que, não é somente com a educação que se modifica uma sociedade. Mas por meio dessa, é possível o fortalecimento de uma consciência que se oponha à tal violência. 
Portanto, a educação inclusiva propõe a modificação da escola, de forma que possa superar todos os obstáculos à aprendizagem (BOOTH e AINSCOW, 2002), pelo convívio com as diferenças, com as minorias, no combate ao preconceito e, consequentemente a discriminação. O preconceito apresenta uma dimensão inconsciente e, é possível que o mero convívio não seja capaz de eliminá-lo. Porém o contato, tende a minimizar a violência (VALA e MONTEIRO, 1996).

A implantação de uma educação inclusiva, torna-se importante pois, é legítima a luta por uma sociedade mais justa. Porém há que se desconsiderar os limites da atual educação, no que se refere à formação e sua próprias condições objetivas. É preciso considerar muito mais do que a simples inclusão. É preciso nos preocuparmos também com a qualidade da educação. O quanto está contribuindo para a formação de indivíduos mais conscientes e críticos. Se essa crítica se relaciona com a necessidade de uma sociedade mais justa, este já se constitui num elemento formador. O papel do professor neste caso torna-se fundamental, pois não é apenas uma questão de transmitir conhecimentos, mas da forma como se lida com esse saber. Essa forma de transmissão aqui referida, em nada se refere a técnicas, mesmo essas imprescindíveis, mas sim ao engajamento do docente, e à sua cumplicidade durante o aprendizado do aluno. São os seus princípios políticos e éticos.

Algumas pesquisas tem demonstrado a importância do professor numa educação inclusiva. Segundo Cook, Tankersley, Cook e Landrun (2000), alunos eu apresentam dificuldades de aprendizagem, normalmente tendem a serem rejeitados por alguns professores, e esses autores propõem que a atitude do professor seja também considerada, quando da implantação e desenvolvimento d e um ensino que se proponha inclusivo. Conforme os autores citados, os comportamentos menos adequados de alguns alunos, bem como seu aprendizado mais lento, tendem a gerarem atitudes de desconforto nos professores, em relação a eles. León (1994) também se preocupou com a dificuldade dos docentes, em lidarem com alunos portadores de necessidades educativas especiais. Propôs estudos acerca de quais os possíveis fatores que podem vir a afetá-los na relação com tais alunos.

Beyer (2005) refere pesquisa na qual, as entrevistas com professores em educação inclusiva indicam que alguns poucos docentes são favoráveis à educação segregada. A diferença entre educação integrada e a educação inclusiva, é citada por Vivarta (2003), que orienta ser a primeira, a que aceita os alunos com deficiência, para isso faz-se algumas 
Id on Line Revista Multidisciplinar e de Psicoloqia

Id on Line Multidisciplinary Journal and Psycology

alterações importantes, seja nas condições ambientais, seja na atenção a tais alunos, mas não faz grandes modificações que incidam sobre os alunos em geral. Este seria o caso da educação inclusiva, propondo novas modalidades de ensino. No caso, que dêem mais ênfase a trabalhos em grupo, a metodologias ativas e avaliações diferenciadas, para atender a todos os alunos (MITTLER, 2003).

Monteiro e Castro (1997) demonstraram que as expectativas dos alunos com experiência, junto com a colegas com deficiência e, os que não possuem essa experiência de convivência, são distintas. No estudo que relatam, paradoxalmente, alunos com experiência com outros alunos com deficiência intelectual, mostraram uma atitude mais contrária a tal aluno, do que outros que não tinham essa experiência. Os resultados levaram as autoras a supor que, somente o contato de um aluno com deficiência, com outros não bastava. Seria importante também outras interferências, de forma a que esse aluno pudesse formar uma imagem mais favorável por parte dos colegas. Certamente, o docente, nestes casos, é o principal agente na sala de aula. Ele, através de sua atitude, teria condições de motivar os alunos sem deficiência, a uma atitude mais empática em relação àqueles que as têm. Assim, não bastaria a experiência do contato (com os alunos com deficiência) para que ocorra a inclusão. É preciso a intervenção do professor.

Tal premissa já é verdadeira na educação em geral. Portanto é possível que ocorra também e mais efetivamente na educação inclusiva.

É verdade que escolas privadas que são financiadas com dinheiro público, muitas vezes tendem a recusarem os alunos ditos problemáticos. Não o fazem formalmente, mas de maneira velada, onde o alunado mais problemático é encaminhado as escolas públicas. Talvez isso explique uma maior concentração de minorias e pessoas com necessidades educativas especiais, nos centros públicos. De certa maneira, tanto os colégios públicos como os privados, tentam evitar esse tipo de aluno. Apenas nos colégios privados, o diretor decide sobre isso e, nos colégios públicos, quem decide é uma direção gestora. O MEC é capaz de impor suas normativas aos colégios públicos, mas não necessariamente aos privados. (ZIBAS, 1999, p. 241)

No Brasil, Jannuzzi (2004) entende que, à medida que a escola inicia o processo de inclusão dos indivíduos, que antes eram marginalizados, vai se uniformizando a forma de tratamento. Em estudo realizado com futuros educadores, alunos de licenciatura, dados foram 
Id on Line Revista Multidisciplinar e de Psicoloqia

Id on Line Multidisciplinary Journal and Psycology

coletados, que indicaram haver relação entre o preconceito e as atitudes contra a educação inclusiva. Também observou-se que a correlação obtida foi significativa, o que seria indicativo de veracidade para a hipótese. Mesmo assim, trata-se de discussão recente, que carece de mais estudos para que se tenha uma posição mais plausível, a respeito da educação inclusiva.

Outro aspecto que deve ser mencionado como importante é sobre a transmissão de conhecimentos ou sobre a formação e o desenvolvimento das habilidades, nos alunos que apresentam necessidades educativas especiais. Nestes casos, talvez possam ser consideradas até menos relevantes, do que mesmo a socialização. Klingner e Vaughn (1999) chegaram a concluir que, sejam os alunos com ou os sem dificuldades, o que mais necessitam é de tratamento igual dos seus professores, bem como da escola. Isto é, precisam que todos sejam tratados com equidade, submetidos às mesmas atividades, e aos mesmos materiais didáticos e, as mesmas atividades em grupo, relativizadas as possibilidades individuais. Eles não ignoram que o professor adapte os seus métodos ou gaste mais tempo para explicar alguma atividade para aqueles alunos que não alcançam certo ritmo para entender determinado assunto. Parecem gostarem de auxiliar os colegas que apresentam-se com mais dificuldades. Além disso preferem os trabalhos em grupo que incluam alunos com e sem dificuldades.

\section{Considerações finais}

A literatura parece apresentar uma espécie de tendência para uma maior discussão sobre a educação inclusiva. Como esta já faz parte de um movimento maior de inclusão social, parecem ser os professores mais favoráveis a essa tendência.

De uma forma mais abrangente, não apresentaram grandes obstáculos para a sua implementação. Mas, ao mesmo tempo em que a julgam necessária, carecem de uma formação mais especializada nesta área do conhecimento. Parecem ainda considerar esses novos alunos hoje inseridos nas classes regulares, como substancialmente distintos daqueles alunos sem deficiência.

A questão que ora está posta, não vem a negar que novas dificuldades possam aparecer ante as significativas diferenças desses novos alunos. Porém, a preocupação, é que eles sejam considerados como obstáculos, antes mesmo da vivência. Dessa forma, poderia configurar-se 
uma atitude preconceituosa. Não se pode partir do pressuposto da homogeneidade de capacidade dos alunos.

Quando a pessoa não responde adequadamente ao que se espera socialmente dela, atribui-se a responsabilidade da suposta falha a própria pessoa. Passa-se então a encaminhar para especialistas, com a suposta habilidade de "curar". Tal pressuposto configura-se num verdadeiro obstáculo a qualquer iniciativa inclusiva. Esta última trás no seu bojo a perspectiva avançada de que todos somos capazes, desde que sejam proporcionadas as condições adequadas.

Booth e Ainscow (2002) acreditam numa mudança de atitude para que possamos verdadeiramente enfrentar os problemas educacionais, não apenas os relacionados à educação inclusiva, mas outros, como questões políticas, que porventura também possam promover um maior desenvolvimento cognitivo, social e humano.

A igualdade de possibilidade frente a necessidade do aprender, apesar das diferenças, é algo simbólico. Um marco em uma sociedade democrática. As diferenças não desaparecerão, mas podem permitir que todos possam participar equitativamente do processo social.

A proposta de inclusão social presente na educação inclusiva, parece estar, cada vez mais, se fortalecendo, desenvolvendo vínculos mais sólidos entre as pessoas e envolvendo todos numa teia global de humanização, cujos limites não parecem ainda demarcados. São avanços importantes para a qualidade da educação que pretendemos conquistar.

\section{Referências}

ADORNO, T. W. Teoría de la seudocultura In T. W. Adorno, Filosofía y superstición (pp. 141174). Madrid: Alianza Editorial, 1972. (Trabalho original publicado em 1959)

ADORNO, T. W. Educação após Auschwitz. In T. W. Adorno, Educação e emancipação (pp. 119-138). Rio de Janeiro: Paz e Terra, 1995. (Trabalho original publicado em 1967)

ADORNO, T. W. Educação e emancipação. In T. W. Adorno, Educação e emancipação (pp. 119-138). Rio de Janeiro: Paz e Terra, 1995. (Trabalho original publicado em 1969)

ADORNO, T. W. Educação para quê? In T. W. Adorno, Educação e emancipação. Rio de Janeiro: Paz e Terra, 1995. (Trabalho original publicado em 1967) 
Id on Line Revista Multidisciplinar e de Psicoloqia

Id on Line Multidisciplinary Journal and Psycology

ADORNO, T. W. Progresso. In T. W. Adorno, Palavras e sinais (pp. 37-61). Petrópolis, RJ: Vozes, 1995.(Trabalho original publicado em 1964)

APPLe, M. W. Podem as pedagogias críticas sustar as políticas de direita? Cadernos de Pesquisa (116), 2002, p. 107-142.

BEYER, H. O. Inclusão e avaliação na escola. Porto Alegre: Mediação, 2005.

BENJAMIN, W. Sobre alguns temas em Baudelaire. In Charles Baudelaire: umlírico no auge do capitalismo (J. Martins Barbosa e H. Alves Baptista, trads.). São Paulo: Brasiliense, 1989. (Trabalho original publicado em 1938)

BOOTh, T., e AINSCOW, M. Index para a inclusão (Reino Unido: CSIE, 2002. Versão produzida e traduzida pelo LAPEADE -Laboratório de Pesquisa, Estudos e Apoio à Participação e à Diversidade em Educação). Rio de Janeiro: Universidade Federal do Rio de Janeiro, 2002.

COOK, B. G., TANKERSLEY, M., COOK, L., e LANDRUN, T. J. Teacher's attitudes toward their included students with disabilities. Exceptional Children, 67(1), 2000, p. 115-135.

HORKHEIMER, M., e ADORNO, T. W. Preconceito. In Temas básicos de sociologia (pp.172-183). São Paulo: Cultrix, 1978.

HORKHEIMER, M., e ADORNO, T. W. Dialética do esclarecimento. Rio de Janeiro: Jorge Zahar, 1985. (Trabalho original publicado em 1947)

JANNUZZI, G. M. Educação do deficiente no Brasil. São Paulo: Autores Associados, 2004.

KLINGNER, J. K., e VAUGHN, S. Student's perceptions of instruction in inclusion classrooms: Implications for students with learning disabilities. Exceptional Children, 66(1), 1999, p. 23-37.

LEÓN, M. J. La perspectiva del profesor tutor sobre los problemas de la integración de los niños con necesidades educativas especiales. Revista de Educación Especial, (18), 1994, p.7783.

LESSA, C. et al. Pobreza e política social: a exclusão nos anos 90. Praga: Estudos Marxistas, anol(3), 1997, p. 63-87.

MARTINS, J. S. Exclusão social e a nova desigualdade. São Paulo: Paulus, 1997.

MARX, K. O capital: crítica da economia política (Livro I, Vol. 1). São Paulo: Difel, 1984. (Trabalho originalpublicado em 1867)

MITTLER, P. Educação inclusiva: contextos sociais. Porto Alegre: Artmed, 2003. 
Id on Line Revista Multidisciplinar e de Psicoloqia

Id on Line Multidisciplinary Journal and Psycology

MONTEIRO, M. B., e CASTRO, P. Cada cabeça sua sentença. Oeira: Celta, 997.1

SANS DEL RIO, S. Integración de alumnos con necesidades educativas especiales: panorama internacional. Madrid: Artegraf, 1996.

VALA, J., e MONTEIRO, M. B. Psicologia social. Lisboa: Fundação Calouste Gulbenkian, 1996.

VIVARTA, V. Mídia e diversidade. Brasília, DF: ANDI/ Fundação Banco do Brasil, 2003.

ZIBAS, D. M. L. A reforma educacional espanhola: entrevista com Mariano Enguita e Gimeno Sacristán.Cadernos de Pesquisa da Fundação Carlos Chagas, (108), 1999, p.233-248.

\section{Como citar este artigo (Formato ABNT):}

FERREIRA, E.L.; TIMÓTEO, E.I.; BEZERRA, M.M.M. Inclusão: Percepção de Professores. Id on Line Revista Multidisciplinar e de Psicologia, Outubro de 2016, vol.10, n.31, p. 154-162. ISSN 1981-1179.

Recebido: 13/08/2016.

Aceito: $17 / 08 / 2016$ 